\title{
Willingness to Join and Pay for Community-Based Health Insurance Among Rural Households of Selected Districts of Jimma Zone, Southwest Ethiopia
}

\author{
Muluneh Getachew \\ Garedew' \\ Shimeles Ololo Sinkie \\ Dejene Melese Handalo' \\ Waju Beyene Salgedo' \\ Kidus Yitebarek Kehali (D) \\ Feyera Gebissa Kebene (D) \\ Tesfaye Dagne \\ Waldemarium' \\ Mahlet Atlaw Mengesha $\left(\mathbb{D}^{2}\right.$ \\ 'Department of Health Policy and \\ Management, Faculty of Public Health, \\ Institute of Health, Jimma University, \\ Jimma, Ethiopia; ${ }^{2}$ School of Public Health, \\ Mekelle University, Mekelle, Ethiopia
}

This article was published in the following Dove Press journal: ClinicoEconomics and Outcomes Research

Background: Globally, millions of people suffer and die because they do not have the money to pay for health care. A voluntary health insurance scheme is a prepayment mechanism to overcome the financial hardship of poor households. There is a high demand to determine the enrolment rate and ability to pay before scale-up of the scheme by the government to be sure of its feasibility and sustainability.

Objective: To determine willingness to join and pay for a community-based health insurance scheme and associated factors among rural households of selected districts in Jimma Zone, 2018. Methods: A community-based cross-sectional study design was employed in selected districts of Jimma Zone, Ethiopia. Multistage simple random sampling was used to select 422 households. Data were collected using a semi-structured interviewer-administered questionnaire. A double bounded contingent valuation method was applied to elicit households' willingness to pay for the scheme. Data were entered into Epi-Data 3.1 and analyzed with SPSS V.23. A binary logistic regression model was fitted to determine the presence of statistically significant associations between the dependent and independent variables at $p$-value $<0.05$ and AOR values with $95 \% \mathrm{CI}$. Results: Of 422 sampled respondents, 389 participated in this study with a response rate of $92 \%$. Of these, 305 (78\%) were willing to join and 274 (90\%) of them were willing to pay. The average amount of money the households were willing to pay per household per annum was 228 ETB (8.27 USD), with a range of 100-500 ETB. The older age groups, poor households, and experience of local risk-sharing schemes were found to be determinants for willingness to join the community-based health insurance. Similarly, having a large family size, and low economic and education status of households were significant predictors of willingness to pay for this scheme.

Conclusion: A high proportion of households were willing to join and pay for the CBHI scheme. The average amount of money they were willing to pay for the scheme was very slightly lower than what is planned by the government. Thus, the government of Ethiopia should strengthen efforts to scale up this scheme in the rural areas of the country specifically to districts not yet enrolled, to reduce direct out-of-pocket payment at service delivery points. This will also contribute to guaranteeing dwellers of rural areas access to quality health services without facing financial hardship, to achieve universal health coverage for all by the end of 2035 .

Keywords: community-based health insurance, willingness to join, willingness to pay, Jimma

\section{Introduction}

Garedew

Email getmuluneh@yahoo.com

Shimeles Ololo Sinkie

Email shimelessos@yahoo.com
Globally, many families suffer excessive financial hardship due to receiving the health care that they need. About 150 million people globally incur catastrophic spending annually, whereas 100 million people are pushed below the poverty line. ${ }^{1,2}$ Almost 
$12 \%$ of the world's population spent at least $10 \%$ of their household income to pay for health care. ${ }^{3}$

In low- and middle-income countries, more than $35 \%$ of health spending per country comes from out-of-pocket expenses. ${ }^{4}$ Especially in Africa, it is the poorest people who pay comparably most for health care. In the 20 countries of African region, the out-of-pocket expenditure of households makes up over $40 \%$ of total health expenditure. ${ }^{5}$ For instance, in Ethiopia, 34\% of health expenditure is generated from households. ${ }^{6}$

However, the World Health Organization (WHO) recommends direct payments should be less than $15-20 \%$ of total health expenditure, as this helps to reduce the incidence of financial catastrophe shock to negligible levels. Due to this, WHO advises moving away from direct out-of-pocket payments to use prepaid mechanisms to raise funds for health. ${ }^{7}$

Among the prepaid mechanisms, health insurances improve access to quality health-care services, protecting households from health-related financial risks, and ultimately improving the health status of the poor. ${ }^{8}$ Of these, community-based health insurance (CBHI) is one means of pooling risks across different population groups so that it significantly reduces the financial burden of catastrophic illnesses for individuals. ${ }^{9}$ CBHI reduces direct out-ofpocket payment at the point of service delivery and improves cost recovery, though its effect on crosssubsidy is questionable. It appears to be the most appropriate insurance model for employees of informal sectors and households of rural areas since their income is unpredictable. $^{10}$

Health-care financing in Ethiopia has been characterized by low government spending, strong reliance on out-of-pocket expenditure, inefficient and inequitable utilization of resources, and poorly harmonized and unpredictable donor funding over the years. ${ }^{11}$ Different health-care financing reforms, such as revising user fees, exemptions and fee waivers, revenue retention, and outsourcing of non-clinical services, have been tried so far but have not yet tackled the challenges. ${ }^{12}$

Recently, the government of Ethiopia has announced two health insurance schemes as a strategy to reduce large out-of-pocket payments for health care and to overcome financial barriers to accessing health care. ${ }^{12}$ Among these, $\mathrm{CBHI}$ has been piloted in selected districts, which reported an enrollment rate of $52 \% .{ }^{12,13}$

Few studies done in Ethiopia indicated that higher rate of willingness to join (WTJ), which was $78 \%$ in Bench Maji ${ }^{14}$ and $80 \%$ in Fogera districts. ${ }^{15}$ Similar studies carried out in the northwestern ${ }^{18}$ and capital city $^{19}$ of Nigeria, and Ecuador $^{20}$ revealed that WTJ was $96 \%, 90 \%$, and $69.3 \%$, respectively. Moreover, willingness to pay (WTP) for this voluntary health insurance was $39.7 \%$ in Adama districts ${ }^{16}$ and $79 \%$ in the two districts of the Amhara region. ${ }^{17}$ From these studies, factors considered as determinants for willingness to join and pay include demographic and socioeconomic, health status, participation in social networks, and perception of individuals toward the insurance scheme. ${ }^{14-17}$

The mean WTP elicited by the double bounded contingent valuation method was 187.4 Birr, 211 ETB (US $\$ 10.5)$, and US\$16 per annum per household in various districts of Ethiopia. ${ }^{15-17}$ Similarly, the average amount of money that households were willing to pay for the scheme was US $\$ 30$ in a rural part of Ecuador. ${ }^{20}$

From this empirical evidence, there is a wide discrepancy in the level of willingness to join and pay for the proposed CBHI scheme. ${ }^{14-17,30,31}$ In addition, the government has also made revisions to the premium amount paid by households. Previous premium contribution was $180 \mathrm{ETB},{ }^{13}$ which is now revised to $240 \mathrm{ETB}^{32}$ per household per annum. This indicates that willingness to join and pay are time-variant variables, which need to be studied to make evidence-based decisions before endorsing the scheme in areas not yet enrolled in it. Moreover, the government of Ethiopia aspires to achieve universal health coverage for its citizens by the end of $2035 .^{21}$ To meet this, the scale-up of voluntary health insurance schemes in all rural parts of Ethiopia is considered as one strategy. ${ }^{29}$ To this end, there should be ample evidence on the demand for CBHI among rural dwellers for health planners and program implementers. Thus, the aim of this study was to determine the level of willingness to join and pay for CBHI and associated factors among rural households of selected districts of Jimma zone.

\section{Methods and Materials}

A community based cross-sectional study design was employed from March 19 to April 1, 2018, in the rural community of selected districts in Jimma Zone, which is located southwest of Addis Ababa. The zone hosts 21 districts with a total of 532 kebeles (the smallest administrative unit) with a total projected population of 3,090,112, of which $89.69 \%$ are rural inhabitants (Jimma Zonal Health Department; Annual Health Report; Unpublished Work; 2017).

All rural households in the six districts that had not yet established the CBHI scheme were the source population, 
while the study population comprised the sampled households in these districts. Household heads who had lived for more than six months in the kebele and who were $\geq 18$ years of age were included in the study. Respondents who were working in the formal sectors or who were unable to participate in the interview due to their health condition were excluded from the study.

The sample size was calculated using a single population proportion formula with the following assumptions: the proportion of households' WTJ $(\mathrm{P}=78 \%)$ in the Bench Maji Zone, Ethiopia, ${ }^{14}$ using 95\% confidence interval $(Z=1.96)$ and $5 \%$ margin of error. After considering a design effect of 1.5 and adding $10 \%$ for potential nonresponse rate, the final sample size was 422 households.

A multi-stage sampling technique was used to select study participants. At the first and second stages, the two districts (Shebe-Sonbo and Sigmo districts) and twelve kebeles (six from each district) were randomly selected using a lottery method out of the zone and also proportional allocation was utilized to determine the number of households from each district and kebele. Finally, simple random sampling was employed to select study participants by their name using computer-generated random numbers in an Excel spreadsheet (Microsoft Corporation, 2013) from the sampling frame.

Dependent variables were the level of willingness to join and pay for CBHI among rural households of Jimma Zone. Independent variables included demographics (age, sex, religion, marital status, family size, ethnicity), socioeconomic variables (wealth status, occupation, education status), health and health-care utilization (illness experience within the past three months, seeking treatment, place of treatment, medical expense and coping mechanism of expenditure, chronic illness, and disabilities) as well as exposure to, and perception of, the schemes (awareness about the scheme, information source, participation in indigenous insurance scheme).

Willingness to join is defined as the motive of rural household heads to enroll in voluntary health insurance to gain benefits from the scheme regardless of the amount of payment and assessed by close-ended binary questions after explaining the actual scenario of the scheme. Willingness to pay means the maximum (non-zero) amount that households are willing to pay for the insurance scheme, elicited through a double bounded contingent valuation method specifically by applying a bidding game. ${ }^{8,22}$ The wealth index questionnaire was adapted from Ethiopian Health Insurance Agency on the number and kinds of consumer goods they own, housing characteristics, and availability of basic amenities for residents. ${ }^{28}$ From these, scores were derived using principal component analysis and were classified into five quintiles.

Face-to-face interviews using semi-structured questionnaires were conducted by eight trained data collectors with diplomas and two senior supervisors with a background in the public health profession who were assigned to monitor the quality of the collected data. First, data collectors explained the actual scenario of CBHI (nature of the scheme, membership criteria, and benefit packages) to the study subjects. This was followed by asking each respondent if they were willing-to-join for the proposed CBHI scheme. Willingness to pay was elicited using a double bounded contingent valuation method by asking if they would pay the premium amount set by the government including registration fee, 250 ETB (240 ETB premium amount and 10 ETB for registration), ${ }^{32}$ and asking follow-up questions based on their first response.

In this bidding game, study participants were asked if they would pay an initial bid amount (250 ETB) and probing questions depend on their response to this bid. If they said "no" for the initial bid, the participants were asked for their reasons for being unwilling to pay. In contrast to this, if they answered "yes," then they were asked if they would pay 300. Next, if their answer was yes, again for 350 . If they still responded yes, they were further asked to state the maximum amount that they would be willing to pay. However, if their response was "no" to any of the next higher bid values, the previous bid amount was taken as the maximum willingness to pay for the respondents. On the other hand, if the respondent's answer to the first bid amount (250 ETB) was "no," they were asked if they were willing to pay 200. If they again responded "no," they were further asked for 150. If they still said "no," they were asked to state the maximum amount that they were willing to pay. But if the response was "yes" to any of the lower bids, that bid amount was taken as the maximum amount that the respondents were willing to pay.

The questionnaire for the survey was first prepared in the English language, then translated into Afan Oromo and back-translated into English to check for consistency. Training was given for one day for the data collectors and supervisors. The pre-test was conducted in Merewa Kebele (outside of the studied districts but near to Jimma Town in the east direction) by taking $5 \%$ of the total sample size ( 21 households) before the actual data collection period and proper modifications were done based on the feedback. 
Every day after data collection, questionnaires were reviewed and checked for completeness by the supervisors.

Data were coded and entered into Epi-data version 3.1 and transported into SPSS version 23.0. After cleaning data for inconsistencies and missing values in SPSS, descriptive statistics such as mean, median, frequency, and proportion were done. Principal component analysis was done after checking all of its assumptions to calculate the wealth index of study participants, which were grouped into quintiles (1st, 2nd, 3rd, 4th and 5th). Bivariate analysis was done using binary logistic regression. All independent variables which had an association with the outcome variable at $p$ a -value of less than 0.25 were chosen for multivariate analysis. Then, multivariate analysis using the enter method was done to determine the presence of statistically significant associations between independent variables and the outcome variables at $p$-values less than or equal to 0.05 and AOR with $95 \%$ CI. Collinearity was checked using a collinearity matrix, with all values of variance inflation factors (VIF) less than 3.6 (cutoff point for VIF $<10$ ). The goodness of fit of the model was assessed using the Hosmer and Lemeshow test, which indicated the non-significant chi-square ( $p$-value of 0.215). This indicates that the model was appropriate for data analysis. The results are presented in the form of tables, figures, and text using frequencies and summary statistics.

Ethical clearance was obtained from the Institutional Review Board (IRB) of the Institute of Health, Jimma University. A letter of permission was obtained from the zonal health department to the respective districts. Informed verbal consent was taken from respondents prior to the interview by explaining the purpose of the study as IRB of Jimma University had already accepted and approved it. The confidentiality of their information was assured using a coding system and by removing any personal identifiers. The right of respondents to refuse to answer several or all of the questions was respected.

\section{Results}

\section{Description of Study Participants}

From 422 sampled respondents, 389 participated in this study, providing a response rate of $92 \%$. The median age of the respondents was $38(\mathrm{SD} \pm 11.59)$, with a range of 18-70 years. Out of the total participants, 280 (72\%) were male, $165(42.4 \%)$ reported that they could only read and write in terms of educational status, and 373 (95.9\%) were married. The majority of study subjects $(320,82.3 \%)$ were Oromo in ethnicity, and $263(67.6 \%)$ were Muslim. The mean family size was 5.46 , with a range of 2-9 members. More than one-fifth $(21.6 \%)$ of the respondents were categorized in the third wealth quintile (Table 1).

Table I Demographic and Socio-Economic Characteristics of Study Participants in Shebe-Sonbo and Sigmo Districts, Jimma Zone, Southwest Ethiopia, March-April 2018

\begin{tabular}{|c|c|c|}
\hline Characteristics $(n=389)$ & Frequency & Percentage \\
\hline \multicolumn{3}{|l|}{ Age } \\
\hline $18-29$ & 53 & 13.6 \\
\hline $30-39$ & 145 & 37.3 \\
\hline $40-49$ & 94 & 24.2 \\
\hline $50-59$ & 53 & 13.6 \\
\hline$\geq 60$ & 44 & 11.3 \\
\hline \multicolumn{3}{|l|}{ Sex } \\
\hline Male & 280 & 72.0 \\
\hline Female & 109 & 28.0 \\
\hline \multicolumn{3}{|l|}{ Religion } \\
\hline Muslim & 263 & 67.6 \\
\hline Orthodox & 90 & 23 \\
\hline Protestant & 23 & 5.9 \\
\hline Others $^{\mathrm{a}}$ & 13 & 3.3 \\
\hline \multicolumn{3}{|l|}{ Ethnicity } \\
\hline Oromo & 320 & 82.3 \\
\hline Keffa & 61 & 15.7 \\
\hline Others $^{b}$ & 8 & 2.1 \\
\hline \multicolumn{3}{|l|}{ Marital status } \\
\hline Married & 373 & 95.9 \\
\hline Others ${ }^{c}$ & 16 & 4.1 \\
\hline \multicolumn{3}{|l|}{ Occupation } \\
\hline Farmer & 282 & 72.5 \\
\hline Merchant & 83 & 21.3 \\
\hline Laborer & 24 & 6.2 \\
\hline \multicolumn{3}{|l|}{ Educational status } \\
\hline Cannot read and write & 133 & 34.2 \\
\hline Only read and write & 165 & 42.4 \\
\hline Primary and above & 91 & 23.4 \\
\hline \multicolumn{3}{|l|}{ Family size } \\
\hline $\mathrm{I}-5$ & 203 & 52.2 \\
\hline$>5$ & 186 & 47.8 \\
\hline \multicolumn{3}{|l|}{ Wealth quintile } \\
\hline Ist quintile (poorest) & 77 & 19.8 \\
\hline 2nd quintile & 78 & 20.1 \\
\hline 3rd quintile & 84 & 21.6 \\
\hline 4th quintile & 72 & 18.5 \\
\hline 5th quintile (richest) & 78 & 20.1 \\
\hline
\end{tabular}

Notes: ${ }^{\mathrm{a}}$ Catholic and Waqefata, ${ }^{\mathrm{b}}$ Tigre and Gurage, ' single, divorced, widowed. 


\section{Health Status and Health-Care Utilization of Respondents}

More than half $(53.5 \%)$ of the respondents rated their perceived health status as good. One hundred sixty-eight $(43 \%)$ of them reported that they encountered illness during the past 3 months. Of 168 study subjects who were ill, $150(89.3 \%)$ sought and got medical care and 87 (58\%) received treatment at a health center. Of 150 study participants, 109 (72.7\%) considered out-of-pocket expenditure to be difficult for them. Among those who considered health-care cost to be very difficult and difficult, 44 (33.6\%) and $26(19.8 \%)$ of them paid this cost by selling their capital assets, and by borrowing from others, respectively (Table 2).

\section{Exposure to and Perception Towards CBHI}

Only less than one-third $(121,31 \%)$ of the study subjects had ever heard of CBHI. Radio was the dominant source of information for nearly all (98.3\%) respondents. Among those who had the information, 48 (39.7\%) of them had the perception that the premium for the insurance scheme should be shared between individuals and the government. Meanwhile, nearly two-thirds $(60.3 \%)$ perceived that individuals alone should pay for the CBHI scheme. Three hundred sixty-six (94.1\%) of the households were taking part in at least one of the indigenous community insurances or social networks (such as Iddir and Iqub) (Table 3).

\section{Willingness to Join and Pay for $\mathrm{CBHI}$}

Three hundred five (78.4\%) of rural household heads were willing to join CBHI, if it would be established in their community. Among participants who had WTJ, 274 $(89.9 \%)$ were also willing to pay for this proposed health insurance scheme (Figure 1).

\section{Amount of Premium Willing to Pay for $\mathrm{CBHI}$} Of 274 respondents, $176(64.2 \%)$ were willing to pay the initial bid amount of $250 \mathrm{ETB}$, which is the premium set by the government. Of these, 53 (19.3\%) participants who were willing to pay the initial bid were also willing to pay the first higher bid of 300 ETB, and 46 (16.8\%) who were willing to pay the first higher bid were also willing to pay the second higher bid amount.

Among those respondents who were not willing to pay the initial bid, $30(10.9 \%)$ were willing to pay the first lower bid of $200 \mathrm{ETB}$, and 45 (16.4\%) who were not willing to pay the first lower bid were willing to pay 150
Table 2 Health Status and Health-Care Utilization of Households in Shebe-Sonbo and Sigmo Districts, Jimma Zone, Southwest Ethiopia, March-April 2018

\begin{tabular}{|c|c|c|}
\hline Variables & Frequency & Percentage \\
\hline \multicolumn{3}{|c|}{$\begin{array}{l}\text { Perceived health status of the } \\
\text { HHs }(n=389)\end{array}$} \\
\hline Poor & 63 & 16.2 \\
\hline Medium & 118 & 30.3 \\
\hline Good & 208 & 53.5 \\
\hline \multicolumn{3}{|c|}{ Chronic illness or disability $(n=389)$} \\
\hline Yes & 76 & 19.5 \\
\hline No & 313 & 80.5 \\
\hline \multicolumn{3}{|c|}{$\begin{array}{l}\text { Experience of illness during the } \\
\text { past three months }(n=389)\end{array}$} \\
\hline Yes & 168 & 43.2 \\
\hline No & 221 & 56.8 \\
\hline \multicolumn{3}{|c|}{$\begin{array}{l}\text { Seeking and get medical care } \\
(n=168)\end{array}$} \\
\hline Yes & 150 & 89.3 \\
\hline No & 18 & 10.7 \\
\hline \multicolumn{3}{|c|}{ Place of treatment $(n=150)$} \\
\hline Public health center & 87 & 58 \\
\hline Private health facility & 28 & 18.6 \\
\hline Public hospital & 26 & 17.3 \\
\hline Others $^{\mathrm{a}}$ & 9 & 6 \\
\hline \multicolumn{3}{|l|}{$\begin{array}{l}\text { Covering the health care } \\
\text { expense }(n=150)\end{array}$} \\
\hline Very difficult & 22 & 14.7 \\
\hline Difficult & 109 & 72.6 \\
\hline Not difficult & 19 & 12.7 \\
\hline \multicolumn{3}{|c|}{$\begin{array}{l}\text { Alternative means if covering } \\
\text { health care expense was difficult } \\
(n=|3|)\end{array}$} \\
\hline Assisted by relatives & 61 & 46.6 \\
\hline Borrow from someone & 26 & 19.8 \\
\hline Sell capital assets & 44 & 33.6 \\
\hline
\end{tabular}

Note: ${ }^{a}$ Self-treatment and traditional medicine.

ETB. From this, the average amount of money the households were willing to pay per household per annum was 228 ETB (8.27 USD at April 2018 exchange rate), with a range of 100-500 ETB (Figure 2).

\section{Factors Associated with Willingness to Join $\mathrm{CBHI}$}

In bivariate analysis, age, educational status, occupation, family size, wealth status, and participation in indigenous community insurances or social networks were found to be 
Table 3 Exposure to and Perception of $\mathrm{CBHI}$ Among Rural Households of Shebe-Sonbo and Sigmo Districts in Jimma Zone, March-April 2018

\begin{tabular}{|c|c|c|}
\hline Variables & Frequencies & Percentage \\
\hline \multicolumn{3}{|l|}{$\begin{array}{l}\text { Ever heard information about } \\
\text { CBHI }(\mathrm{N}=389)\end{array}$} \\
\hline Yes & 121 & 31 \\
\hline No & 268 & 69 \\
\hline \multicolumn{3}{|l|}{ Source of information $(n=121)$} \\
\hline Health extension workers & 2 & 1.7 \\
\hline Radio & 119 & 98.3 \\
\hline \multicolumn{3}{|l|}{$\begin{array}{l}\text { Thought about who should pay } \\
\text { for CBHI }(n=|2|)\end{array}$} \\
\hline Individual/household & 73 & 60.3 \\
\hline Both individual and government & 48 & 39.7 \\
\hline \multicolumn{3}{|l|}{$\begin{array}{l}\text { Perception of respondents about } \\
\text { who advantages from CBHI } \\
(n=|2|)\end{array}$} \\
\hline Poor and sick & 26 & 21.5 \\
\hline Rich and healthy & 6 & 5 \\
\hline All poor, sick, rich and healthy & 89 & 73.5 \\
\hline \multicolumn{3}{|l|}{$\begin{array}{l}\text { Think premium is amount paid } \\
\text { to get compensation for illness } \\
(n=\mid 2 I)\end{array}$} \\
\hline Yes & 97 & 80 \\
\hline No & 24 & 20 \\
\hline \multicolumn{3}{|l|}{$\begin{array}{l}\text { Ever participated in any indigenous } \\
\text { community insurances }(\mathbf{N}=\mathbf{3 8 9})\end{array}$} \\
\hline Yes & 366 & 94 \\
\hline No & 23 & 6 \\
\hline
\end{tabular}

candidate variables ( $p$-value $\leq 0.25$ ). Then, these variables were fitted to multivariate binary logistic regression analysis to identify factors associated with WTJ.

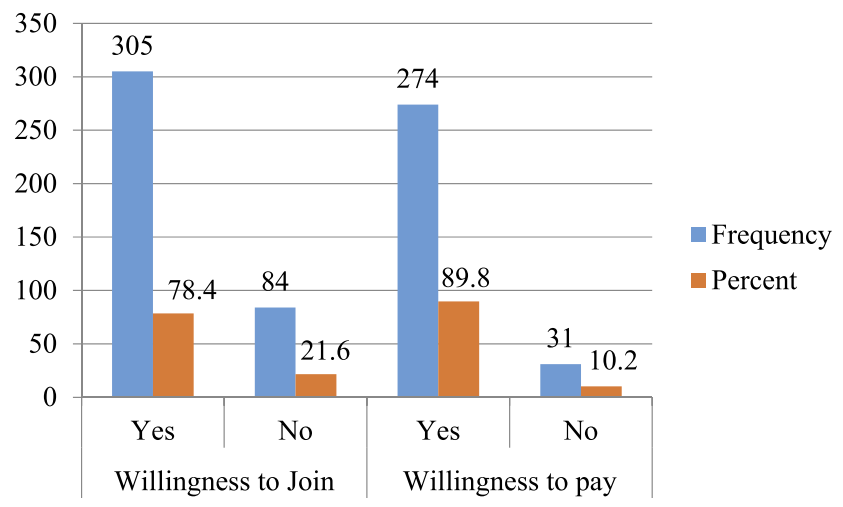

Figure I Willingness to join and pay for $\mathrm{CBHI}$ among rural households of ShebeSonbo and Sigmo districts in Jimma Zone, southwest Ethiopia, March-April 2018.
Older age household heads (60 years and above) were 3.5 times more likely to join the scheme than younger age groups (18-29 years) (AOR=3.55, 95\% CI $[1.00,12.50])$. Participants who can read and write were 4.5 times more likely to join CBHI compared to those who cannot read and write $(\mathrm{AOR}=4.49,95 \% \mathrm{CI}[2.03,9.93])$. Household heads who were considered as poor were 2.5 times more likely to join the scheme than those of the rich households (AOR $=2.47,95 \%$ CI $[1.36,4.48])$. Furthermore, study subjects who were not participating in any indigenous community insurance or social networks were $86 \%$ less likely to enroll voluntary health insurance than their counterparts (AOR $=0.14,95 \%$ CI $[0.05,0.39])$ (Table 4).

\section{Independent Predictors of Willingness to Pay for $\mathrm{CBHI}$}

In bivariate analysis sex, educational status, family size, wealth status, health status, and illness experience were identified as candidate variables ( $p$-value $<0.25$ ) and were considered for multivariate analysis. Households having 1-5 family members were $77 \%$ less likely to pay for the CBHI scheme than those households having five or more family members (AOR $=0.23,95 \%$ CI $[0.09,0.58])$. Poor household heads were $58 \%$ less likely to pay than those who were considered as rich $(\mathrm{AOR}=0.42,95 \% \mathrm{CI}[0.18,0.99])$. Moreover, those respondents who attended primary and above educational were 3.8 times more likely to pay for voluntary health insurance than those who cannot read and write (AOR=4.19, 95\% CI [1.33, 13.18]). Participants who can read and write were 8 times more likely to pay for this scheme compared to those who cannot read and write $(\mathrm{AOR}=8.36,95 \%$ CI $[3.05,22.95])$ (Table 5).

\section{Discussion}

This study revealed that $78.4 \%$ of households were WTJ for proposed CBHI. The current finding is in line with the national enrollment rate $(80 \%)$ by end of $2020,{ }^{29}$ and other studies conducted in Debub Bench (77.8\%) ${ }^{14}$ Fogera districts $(80 \%),{ }^{15}$ and East Gojjam $(81.5 \%) .{ }^{30}$ The result of this study exceeds those of a study done in rural Ecuador, ${ }^{20}$ which reported that $69 \%$ of respondents were willing to join for CBHI. However, it less than studies done in the capital city of Nigeria ${ }^{18}$ and north of Nigeria, ${ }^{19}$ which stated $96 \%$ and $90 \%$ enrollment rates, respectively. This difference might be due to variation in the sample size, study period, knowledge, and perception of participants towards the scheme.

In this study, the age of the study subjects affects the enrollment rate. Older age household heads were more likely 

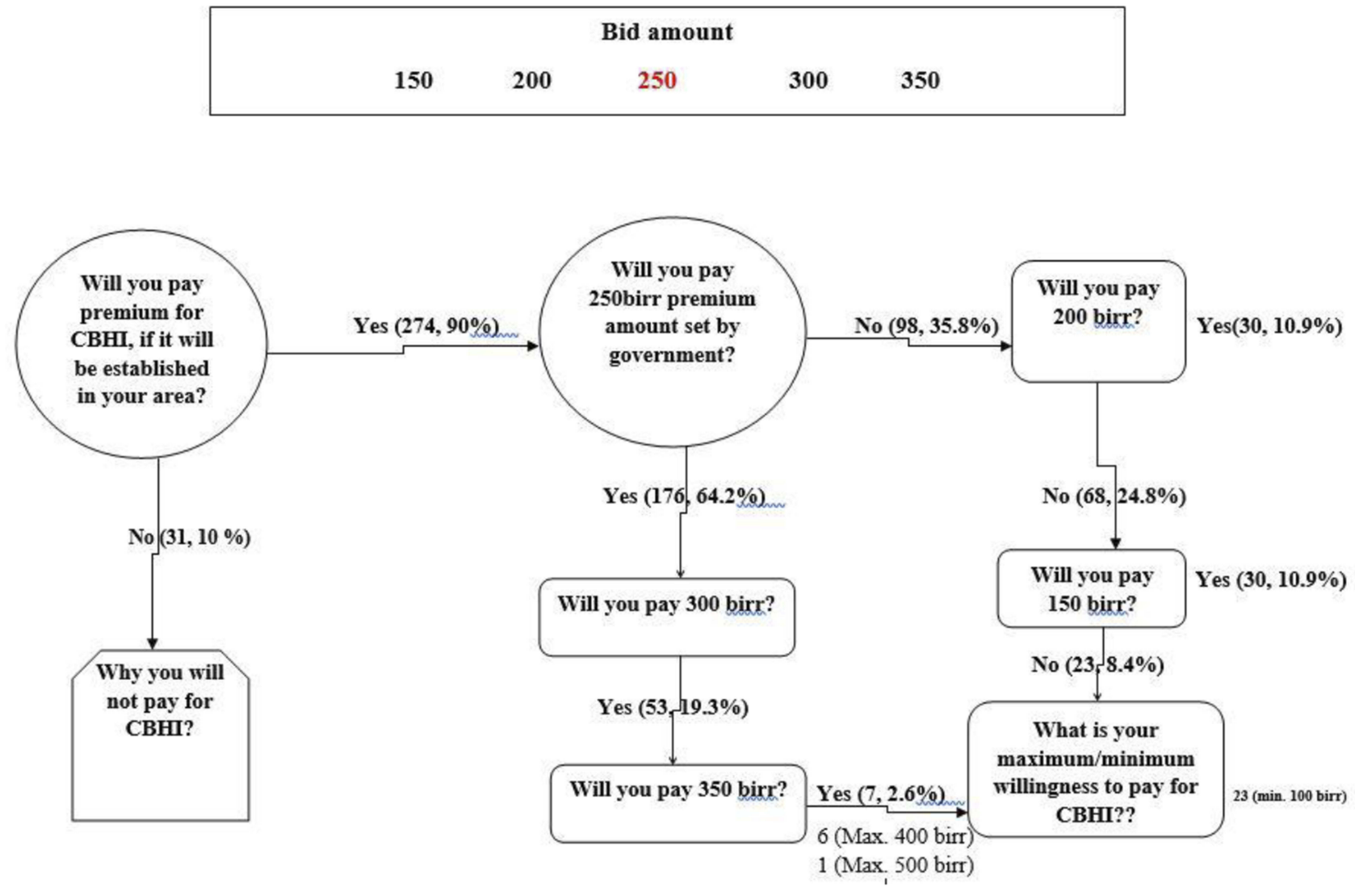

Figure 2 Willingness to pay of respondents of Shebe-Sonbo and Sigmo districts, Jimma zone, southwest Ethiopia, March-April 2018 (I USD=27.56 ETB).

to join the scheme compared to younger age groups. This finding is in line with a study in Burkina Faso, ${ }^{26}$ which revealed that older age household heads were 2.39 more likely to join the scheme. The observed similarity can be explained by the fact that susceptibility to diseases and disability rate are higher among older age groups. This will encourage older age groups to join the CBHI to cover their unexpected health-care costs during their illness. In contrast to this, a study done in Debub Bench Maji Zone reported that older age groups were $6 \%$ less likely to join this insurance than the younger groups. ${ }^{14}$ The possible explanation for this might be due to the difference in the study period and level of awareness among the older age groups. The latter study was done during the early phase of the $\mathrm{CBHI}$ launch and the older age groups of the study area may have had lower access to communication media than the younger groups. We also found that household heads who were categorized as poor were 2.5 times more likely to join the scheme than their counterparts. This finding contradicts the finding from Bench Maji Zone, which stated that rich households were 1.5 times more likely to be willing to join the scheme. ${ }^{14}$ The difference might be related to the ability to make payment, in the latter study the poor households may not be able to cover the premium cost of the scheme; there may also be differences in the access to media in the study area.

The household heads who were not taking part in any indigenous community insurances or social networks were $86 \%$ less likely to join the scheme than households who had participation. This result is similar to findings from Tanzania ${ }^{25}$ and Burkina Faso, ${ }^{26}$ which reported that membership in any risk-sharing network was positively correlated with enrollment. The reason behind this might be that those who were not involved in any risk-sharing mechanism would not develop community solidarity and trust, and not realize the benefits if they were not exposed to it.

In this study, nine out of ten household heads had WTP for community-based health insurance. The recent finding is higher than studies done in the two areas of Nigeria $(82 \%),{ }^{23,24}$ and also studies carried out in Kewiot and Efratana-gedem districts (79\%), ${ }^{17}$ Bugna district $(77.8 \%)^{31}$ and Adama districts $(39.7 \%)^{16}$ of Ethiopia. The possible explanation for the observed variation might be the difference in the socio-economic status of the community, government commitment to advocate the scheme through different 
Table 4 Factors Associated with Willingness to Join for Proposed Community-Based Health Insurance Scheme Among Rural Household Heads of Shebe-Sonbo and Sigmo Districts of Jimma Zone, March-April 2018

\begin{tabular}{|c|c|c|c|c|}
\hline \multirow[t]{2}{*}{ Variables $(n=389)$} & \multicolumn{2}{|c|}{ WTJ CBHI } & \multirow[t]{2}{*}{ COR $(95 \% \mathrm{Cl})$} & \multirow[t]{2}{*}{ AOR $(95 \% \mathrm{Cl})$} \\
\hline & Yes & No & & \\
\hline \multicolumn{5}{|l|}{ Age } \\
\hline $18-29$ & 36 & 17 & I & I \\
\hline $30-39$ & 120 & 25 & $2.27(1.10,4.66)^{*}$ & $1.42(0.62,3.23)$ \\
\hline $40-49$ & 76 & 18 & $1.99(0.91,4.32)^{*}$ & I.42(0.57,3.57) \\
\hline $50-59$ & 34 & 19 & $0.85(0.378,1.89)$ & $0.73(0.27,1.98)$ \\
\hline$\geq 60$ & 39 & 5 & $3.68(1.23,11.01)^{*}$ & $3.55(1.0,12.50)^{* *}$ \\
\hline \multicolumn{5}{|l|}{ Educational status } \\
\hline Cannot read and write & 96 & 37 & 1 & 1 \\
\hline Can read and write & 144 & 21 & $2.6(1.46,4.79)^{*}$ & $4.49(2.03,9.93)^{* *}$ \\
\hline Primary and above & 65 & 26 & $0.96(0.53,1.74)$ & $1.57(0.75,3.28)$ \\
\hline \multicolumn{5}{|l|}{ Occupation } \\
\hline Farmer & 232 & 50 & I & I \\
\hline Merchant & 61 & 22 & $0.60(0.34,1.06)^{*}$ & $\mathrm{I} . \mathrm{I}(0.55,2.20)$ \\
\hline Laborer & 12 & 12 & $\begin{array}{l}0.22(0.092,0.508) \\
*\end{array}$ & $0.48(0.15,1.52)$ \\
\hline \multicolumn{5}{|l|}{ Family size } \\
\hline $1-5$ & 153 & 50 & I & I \\
\hline$>5$ & 152 & 34 & $1.46(0.89,2.39)^{*}$ & $1.19(0.64,2.23)$ \\
\hline \multicolumn{5}{|c|}{$\begin{array}{l}\text { Participation in indigenous community insurance } \\
\text { or social network }\end{array}$} \\
\hline Yes & 296 & 70 & I & I \\
\hline No & 9 & 14 & $0.15(0.06,0.36)^{*}$ & $0.14(0.05,0.39)^{* *}$ \\
\hline \multicolumn{5}{|l|}{ Wealth status } \\
\hline Poor & 165 & 63 & $0.39(0.23,0.68)^{*}$ & $2.47(1.36,4.48)^{* *}$ \\
\hline Rich & 140 & 21 & 1 & I \\
\hline
\end{tabular}

Notes: *Statistically significant at $p$-value $\leq 0.25, * *$ statistically significant at $p$-value $<0.05$.

strategies and increasing awareness levels of communities of the benefit packages of the scheme.

The average amount of money the households were willing to pay per household per annum was 228 ETB (8.27 USD at April 2018 exchange rate). The WTP amount was consistent with a study done in Bugna district (233 ETB), ${ }^{31}$ and slightly lower than the newly proposed government premium (240 ETB). ${ }^{32}$ The current finding is higher than study findings in Fogera districts (187.4 ETB) ${ }^{15}$ and in Adama districts (211 ETB) ${ }^{16}$ However, it is lower than the studies done in Ecuador $^{20}$ and other parts of Ethiopia, ${ }^{17,30}$ which showed that average WTP of US $\$ 30$, US $\$ 16$, and US $\$ 11.12$ per year, respectively. This could be due to difference in the elicitation methods, initial bid, and change of the value of money over the time period.

Study participants who had a few family members were less likely to pay for the scheme compared to their counterparts. This result is supported by studies conducted in Ethiopia ${ }^{17}$ and Nigeria. ${ }^{23}$ This might be due to the fact that households having lower family size may have higher economic status and these households may consider themselves to be able to cover the cost of medical care for their families.

Those households who were considered as poor were $58 \%$ less likely to pay than those who were categorized as rich. This finding is in agreement with other studies done in Fogera districts, ${ }^{15}$ Adama Woreda, ${ }^{16}$ and in districts of the Amhara region ${ }^{17}$ of Ethiopia. Similar findings were also reported from studies done in Nigeria ${ }^{23}$ and Tanzania. ${ }^{25}$ This could be because poor households might not have adequate money that can be reserved to pay as premium. This implies that the government should implement the co-payment system to enable poor households to meet what is required of them. 
Table 5 Predictors of Willingness to Pay for Community-Based Health Insurance Scheme Among Rural Households of Shebe-Sonbo and Sigmo Districts of Jimma Zone, Southwest Ethiopia, March-April 2018

\begin{tabular}{|c|c|c|c|c|}
\hline \multirow[t]{2}{*}{ Variables $(n=305)$} & \multicolumn{2}{|c|}{ CBHI } & \multirow[t]{2}{*}{ COR $(95 \% \mathrm{Cl})$} & \multirow[t]{2}{*}{ AOR $(95 \% \mathrm{Cl})$} \\
\hline & Yes & No & & \\
\hline \multicolumn{5}{|l|}{ Sex } \\
\hline Male & 199 & 18 & I & I \\
\hline Female & 75 & 13 & $0.52(0.24,1.12)^{*}$ & $0.56(0.24,1.30)$ \\
\hline \multicolumn{5}{|l|}{ Family size } \\
\hline $1-5$ & 132 & 21 & $0.44(0.20,0.98) *$ & $0.23(0.09,0.58)^{* *}$ \\
\hline$>5$ & 142 & 10 & 1 & I \\
\hline \multicolumn{5}{|l|}{ Wealth status } \\
\hline Poor & 119 & 21 & $0.37(0.17,0.81)^{*}$ & $0.42(0.18,0.99)^{* *}$ \\
\hline Rich & 155 & 10 & 1 & 1 \\
\hline \multicolumn{5}{|l|}{ Educational status } \\
\hline Cannot read and write & 79 & 17 & I & I \\
\hline Can read and write & 136 & 8 & $3.66(1.51,8.86)^{*}$ & $8.36(3.05,22.95)^{* *}$ \\
\hline Primary and above & 59 & 6 & $2.12(0.77,5.69)^{*}$ & $4.19(1.33,13.18)^{* *}$ \\
\hline \multicolumn{5}{|l|}{ Health status } \\
\hline Poor & 34 & 9 & $0.28(0.11,0.74)^{*}$ & $0.89(0.27,2.99)$ \\
\hline Medium & 105 & 12 & $0.65(0.27,1.56)$ & $1.6 I(0.6 I, 4.2 I)$ \\
\hline Good & 135 & 10 & I & 1 \\
\hline \multicolumn{5}{|l|}{ IIIness experience } \\
\hline Yes & 134 & 20 & $0.53(0.24,1.14)^{*}$ & $0.43(0.18,1.03)$ \\
\hline No & 140 & 11 & 1 & I \\
\hline
\end{tabular}

Notes: *Statistically significant at $p$-value $\leq 0.25, * *$ statistically significant at $p$-value $<0.05$.

We found that household heads who had better educational status were more likely to pay for CBHI. Similar findings were also reported from studies done in Ethiopia, ${ }^{16,17}$ Burkina Faso, ${ }^{26}$ and Nigeria. ${ }^{27}$ This could be because educated individuals might have a better income, access to media and easily understand the benefits of participating in the health insurance scheme.

The interpretation of these findings should take into consideration some limitations related to the double bounded contingent valuation method to elicit willingness to pay as it may not show the actual amount of money the households can pay for a proposed scheme based on their own choice. Some households, who have a better understanding of the benefit packages and interest in implementation of this scheme in the districts may overestimate their premium contributions and the opposite may also be true.

\section{Conclusion}

According to this study, a high proportion of households were willing to join the scheme, meeting government expectations, ${ }^{29}$ which will encourage the scale-up of the
CBHI in rural areas of the country, specifically to those areas not yet enrolled. A significant number of respondents were willing to pay for the proposed voluntary health insurance scheme. This may show that there is a high demand for CBHI among rural residents of the studied districts. Thus, shareholders can consider CBHI as a viable option to cover households' health-care costs and for health financing in rural parts of Ethiopia. The average amount of money that households were willing to pay for this health insurance scheme was very slightly lower than what is planned by the Ethiopian government. ${ }^{32}$ This implies that study participants valued the scheme and recognized that this scheme will help them improve access to quality health care for themselves and their family members.

The older age group, poor households and having experience in local insurance schemes were found to be determinants for WTJ community-based health insurance. This implies that we can consider these segments of the community as early adopters or facilitators during the implementation of CBHI. 
Similarly, larger family size, and lower economic and education status of households were significant predictors of WTP for voluntary health insurance. To help poor households, there should be a subsidy mechanism from the federal government to enhance their utilization of this scheme. Moreover, the government should adjust the premium contribution by taking family size into consideration since having more family members may interfere with the ability to pay and may also deter their utilization of the scheme. The Health Insurance Agency of Ethiopia should design effective communication strategies to overcome challenges posed by low educational status in rural parts of Ethiopia and to ensure equal benefits of the scheme for all those who need it.

In general, there is an improvement in willingness to join and pay for CBHI among rural households of Ethiopia, as indicated by this study and also as widely implied in other recently published works. ${ }^{30,31}$ Thus, the Ethiopian government should strengthen efforts to scaleup this scheme in all studied districts to reduce direct outof-pocket payment at service delivery points. This will also contribute to guaranteeing dwellers of rural areas access to quality health services without facing financial hardship, and to achieving universal health coverage for all by the end of $2035 .^{21}$

Furthermore, scholars should work to address equity and sustainability challenges of the scheme by taking into account households' family size and income using a strong prospective study design.

\section{Abbreviations}

AOR, adjusted odds ratio; CI, confidence interval; CBHI, community-based health insurance; COR, crude odds ratio; ETB, Ethiopian Birr; WHO, World Health Organization; WTJ, willingness to join; WTP, willingness to pay.

\section{Acknowledgments}

We are grateful to Jimma University for funding this research. We also would like to thank rural households of the selected districts for their willingness and participation in this study. In addition, we acknowledge Jimma Zone Health Department for providing us with necessary information on the study areas. Last, but not least, we appreciate Shebe-Sonbo and Sigmo districts health offices for providing us with necessary information on the study participants and areas.

\section{Author Contributions}

All authors contributed to conception and design of the study, acquisition of data, data analysis and interpretation, funding acquisition, drafting and revising the manuscript, gave their final approval for submission and the version to be published, and agreed to be accountable for all aspects of the work.

\section{Funding}

The funding for this study was completely covered under a mega project entitled "Access to essential health services and financial protection in Jimma Zone," which was governed under the Jimma University Postgraduate Research fund project office.

\section{Disclosure}

All the authors declare that they do not have any competing interests, be it financial or non-financial.

\section{References}

1. Xu K, Evans DB, Carrin G, et al. Protecting households from catastrophic health spending. Health Aff (Millwood). 2007;26:972-983. doi:10.1377/hlthaff.26.4.972;

2. Wagstaff A, Flores G, Hsu J, et al. Progress on catastrophic health spending in 133 countries: a retrospective observational study. Lancet Glob Health. 2018;6:e169-e179. doi:10.1016/S2214-109X(17)30429-1

3 . World Health Organization, World Bank. Tracking universal health coverage: 2017 global monitoring report. Available from: http://www.who.int/ healthinfo/universal_health_coverage/report/2017/en/. Accessed January 6, 2020.

4. World Health Organization. Countries are spending more on health, but people are still paying too much out of their own pockets. 2019.

5. World Health Organization in Africa region. State of health financing in the African Region. January 2013.

6. Federal Democratic Republic of Ethiopia Ministry of Health. Ethiopia's Fifth National Health Accounts. Addis Ababa; 2014.

7. World Health Organization. The World Health Report; Health Systems Financing: The Path to Universal Health Coverage. World Health Organization; 2010. Available from: https://apps.who.int/medicine docs/documents/s20169en/s20169en.pdf. Accessed January 15, 2020.

8. Woldemichael A, Gurara DZ, Shimeles A. Community-Based Health Insurance and Out-of-Pocket Healthcare Spending in Africa Evidence from Rwanda. 2016;(9922).

9. Binam JN Willingness to pay in Cameroon: Evidence of rural households. 2007. doi:10.1094/PDIS-91-4-0467B

10. Ekman B. Community-based health insurance in low-income countries. Health Policy Plan. 2004;19(5):249-270. doi:10.1093/heapol/czh031

11. Dibaba A, Hadis M, Ababor S, Assefa Y. Improving Health Care Financing in Ethiopia (SURE policy brief). Addis Ababa, Ethiopia: Ethiopian Public Health Institute; 2014. Available from: https://www. who.int/evidence/sure/pdimprovinghealthcarefinancingethiopia.pdf. Accessed January 15, 2020.

12. USAID. Health Care Financing Reform in Ethiopia: Improving Quality and Equity. 2012.

13. Feleke S, Mitiku W, Zelelew H, Ashagari TD. Ethiopia's CommunityBased Health Insurance: A Step on the Road to Universal Health Coverage. USAID; 2015. Aavailable from: https://www.hfgproject. org/ethiopias-community-based-health-insurance-step-road-universal -health-coverage/. Accessed January 15, 2020. 
14. Haile M, Ololo S, Megersa B. Willingness to join community-based health insurance among rural households of Debub Bench District, Bench Maji Zone, Southwest Ethiopia. BMC Public Health. 2014;14:1-10. doi:10.1186/1471-2458-14-591

15. Kebede A, Gebreslassie M, Yitayal M. Willingness to pay for community based health insurance among households in the rural community of Fogera District, North West Ethiopia. Int J Econ Finance Manage Sci. 2014;2(4):263-269. doi:10.11648/j.ijefm.20140204.15

16. Entele B, Emodi N. Health insurance technology in ethiopia: willingness to pay and its implication for health care financing. Am J Public Health Res. 2016;4(3):98-106.

17. Mamo E, Bekele G. Households' willingness to pay for communitybased health insurance scheme in Kewiot and EfratanaGedem districts of Amhara region, Ethiopia, MTI. Bus Econ Res. 2017;7 (2):2162-4860.

18. Adedeji A, Doyin A, Kayode O, Ayodele A. Knowledge, practice and willingness to participate in community health insurance scheme among households in Nigerian capital city. J Med Sci. 2017;12 (1):9-18

19. Gobir AA, Adeyemi AO, Abubaker AA, Audu O, Joshua A. Determinants of willingness to join community-based health insurance scheme in a rural community of north western Nigeria. AJHE. 2016;5:1-10

20. Eckhardt M, Forsberg BC, Wolf D, Crespo-Burgos A. Feasibility of community-based health insurance in rural tropical Ecuador. Rev Panam Salud Publica. 2011;29(4):177-184.

21. The Federal Democratic Republic of Ethiopia Ministry of Health. Health Sector Transformation Plan; 2015. Available from: https:// www.globalfinancingfacility.org/sites/gff new/files/Ethiopia-healthsystem-transformation-plan.pdf. Accessed January 15, 2020.

22. Kuwawenaruwa A, Macha J, Borghi J. Willingness to pay for voluntary health insurance in Tanzania. East Afr Med J. 2011;88(2):54-64.

23. Onwujekwe O, Onoka C, Kirigia J. Willingness to pay for community-based health insurance in Nigeria: do economic status and place of residence matter? Healthy Policy and Planning. 2010;25:155-161. doi:10.1093/heapol/czp046
24. Bukola A. Willingness to pay for community based health care financing scheme: a comparative study among rural and urban households in Osun state, Nigeria. J Dent Med Sci. 2013;5 (6):27-40

25. Tundui C, Macha R. Social capital and willingness to pay for community based health insurance: empirical evidence from rural Tanzania. J Finance Econ. 2014;2(4):50-67.

26. Cofie P, De Allegri M, Kouyaté B, Sauerborn R. Effects of information, education, and communication campaign on a community-based health insurance scheme in Burkina Faso. Glob Health Action. 2013;6:201791. doi:10.3402/gha.v6i0.20791

27. Babatunde OA, Akande TM, Salaudeen AG, Aderibigbe SA, Elegbede OE, Ayodele LM. Willingness to pay for community health insurance and its determinants among household heads in rural communities in north-central Nigeria. Int Rev Soc Sci Humanitie. 2012;2 (2):133-142.

28. Ethiopian Health Insurance Agency. Evaluation of Community-Based Health Insurance Pilot Schemes in Ethiopia. Addis Ababa: Ethiopian Health Insurance Agency; 2015.

29. USAID and Systems for Improved Access Pharmaceutical and Services. Ethiopian National Health Insurance Scale-Up Assessment on Medicines Financing, Use, and Benefit Management: Findings, Implications, and Recommendations. August 2016.

30. Kibret GD, Leshargie CL, Wagnew F, Alebel A. Willingness to join community-based health insurance and its determinants in East Gojjam zone, Northwest Ethiopia. BMC Res Notes. 2019;12:31. doi:10.1186/s13104-019-4060-3

31. Minyihun A, Gebregziabher MG, Gelaw YA. Willingness to pay for community-based health insurance and associated factors among rural households of Bugna District, Northeast Ethiopia. BMC Res Notes. 2019;12:55. doi:10.1186/s13104-019-4091-9

32. Lavers T. Towards universal health coverage in Ethiopia's 'developmental state'? The political drivers of health insurance. Soc Sci Med. 2019;228:60-67. doi:10.1016/j.socscimed.2019.03.007
ClinicoEconomics and Outcomes Research

\section{Publish your work in this journal}

ClinicoEconomics and Outcomes Research is an international, peerreviewed open-access journal focusing on Health Technology Assessment, Pharmacoeconomics and Outcomes Research in the areas of diagnosis, medical devices, and clinical, surgical and pharmacological intervention. The economic impact of health policy and health systems organization also constitute important areas of coverage. The manuscript management system is completely online and includes a very quick and fair peer-review system, which is all easy to use. Visit http://www.dovepress.com/testimonials.php to read real quotes from published authors.

Submit your manuscript here: https://www.dovepress.com/clinicoeconomics-and-outcomes-research-journal 